
\title{
28 Research Square \\ Efficacy and Safety of Trabectedin in Patients with Soft Tissue Sarcoma: A Bicentric Retrospective Analysis.
}

Chaigneau Loïc ( $\nabla$ Ichaigneau@chu-besancon.fr)

University Hospital of Besançon

Jary Marine

University Hospital of Besançon

Nerich Virginie

University Hospital of Besançon

Hervieu Alice

Centre Georges-François Leclerc

Aubry Sébastien

University Hospital of Besançon

Charon Barra Céline

Centre Georges-François Leclerc

Meynard Guillaume

University Hospital of Besançon

Neumann Florent

University Hospital of Dijon

Kalbacher Elsa

University Hospital of Besançon

Isambert Nicolas

University Hospital of Poitiers

\section{Research Article}

Keywords: Soft tissue sarcoma, trabectedin, efficacy, toxicity

Posted Date: April 28th, 2021

DOI: https://doi.org/10.21203/rs.3.rs-428582/v1

License: (c) (1) This work is licensed under a Creative Commons Attribution 4.0 International License.

Read Full License 


\section{Abstract}

Background: Soft tissue sarcomas (STS) are a rare and heterogenous group of tumors, with poor prognostic, judging from their frequency to relapse. Few drugs are available. Since 2007, trabectedin got approval after failure of anthracyclines and ifosfamide, for advanced or metastatic STS.

Patients and Methods: This retrospective study describes effects of trabectedin on survival, response, and toxicity, in STS patients. One hundred twenty-nine patients treated between 2002 and 2019 were analysed, from two French centers. All patients were tested for toxicities, and efficacy was assessed in patients exposed to at least 2 cycles of trabectedin.

Results: Three median cycles were administered per patient (1-79). Among the 115 patients analysed for efficacy, the median progression free survival was 3.0 months [ $\mathrm{Cl}_{95 \%}: 2.3-4.7$ ], with an overall survival of 11.9 months $\left[\mathrm{Cl}_{95 \%}: 10.2-16.6\right]$. The rate of disease control was $45.2 \%$ at the end of treatment. Myxoid liposarcoma $(n=11)$ was the histology subtype that benefited most from this chemotherapy with median progression free survival and an overall survival of 13.3 months [ $\mathrm{Cl}_{95 \%}: 2.3-18.7$ ] and 27.8 months $\left[\mathrm{Cl}_{95 \%}: 3.2\right.$ - 64.7], respectively. Adverse events were manageable.

Conclusion: Efficacy of trabectedin is confirmed in terms of clinical benefit and low toxicity, especially for myxoid liposarcoma.

\section{Introduction}

Soft Tissue Sarcomas (STS) are a heterogenous group of tumors including more than 80 histological subtypes, the most frequent being liposarcomas and leiomyosarcomas $(1,2)$. However, they represent less than $1 \%$ of all malignancies, and the only curative treatment is surgery, with or without radiation. Despite optimal local therapy, the 5 -years rate of relapse is $40 \%$ (3). At locally advanced or metastatic stage, patients have less than 10\% 5-years overall survival (OS). Systemic chemotherapy remains the standard treatment in a palliative intend: doxorubicin and ifosfamide are the most active drugs in STS, providing as a single agent an overall response rate of $15-35 \%$ and $18-20 \%$, respectively (4-7). As the disease progresses, several chemotherapies and targeted therapies are available with debatable efficacy. Strategy decision of treatment depends on subtype of sarcoma.

Among the available drugs, trabectedin is an antitumor agent derived from a marine source, the Caribbean tunicate Ecteinascidia turbinata, now synthetically produced (8). The way trabectedin works is complex, occurring during gene transcription. Unlike what is expected for a DNA-damaging agent, sensitivity to trabectedin is correlated to a functional nucleotide excision repair system (9).

In France, trabectedin was available - initially through a compassionate use program (ATU) - since 2003, only in referent centers. After September 2007, trabectedin was approved in the European Union for patients with advanced STS after failure of anthracyclins and ifosfamide or for those who are unsuited to 
receive such agents. This approval was based on a phase II study demonstrating a efficacy in terms of response and progression free survival (10) .

A routine assessment is often mandatory to confirm the observed efficiency of new drugs in real world settings. Although randomized clinical trials provide essential responses to assess the clinical benefit of a molecule or treatment regimen, the results of these randomized trials may not be applicable in common practice. Indeed, the results are not easily generalizable to a larger and more heterogeneous population. One must distinguish efficacy, clinical assessment under optimal conditions (based on the inclusion and exclusion criteria specified in randomized trials) and effectiveness, clinical assessment under "real-life" conditions of use. Real-world evidence (RWE) and randomized control trial (RCT) are therefore complementary. The latter mainly provides 2 types of information: first, to what extent the conditions of clinical trials are verified in real life: population actually treated, dosage, adherence... Secondarily, they may highlight side effects - particularly delayed - not observed in clinical trials, due to the limited number of patients included and insufficient follow-up.

The purpose of this paper is then to analyse the use of trabectedin at University Hospital Center of Besançon and Georges François Leclerc Cancer Center of Dijon, respectively in Franche-Comté and Burgundy regions (France). This bicentric retrospective analysis describes the benefit of trabectedin, in terms of response, survival and adverse events, in the different types of STS.

\section{Patients And Methods}

\section{Data extraction}

All consecutive patients treated with trabectedin at University Hospital Center of Besançon and Georges François Leclerc Cancer Center of Dijon, between January 2002 and August 2018, were retrospectively studied.

All patients with histologically proven STS were eligible for this retrospective analysis. Sarcomas other than STS like GIST, Ewing sarcoma or paediatric sarcoma were excluded. Treatment characteristics were captured from the BPC $\circledast$ software or the pharmacy database (chemotherapy lines, type of chemotherapy, trabectedin dosage, cycle delay, treatment interruption, adverse or severe adverse event...). The patient demographic, the disease characteristics, the treatment efficacy and the patient outcome were collected from the patient's medical record.

For each patient, the age at diagnosis, the sex, the performance status (World Health Organisation criteria), the initial disease characteristics (histological subtype and grading, staging of the disease as per "Fédération Nationale des Centres de Lutte Contre le Cancer" criterion, site of the primary disease and sites of metastases) were recorded. Before beginning the trabectedin regimen, the number of previous lines was recorded, as the date of the last chemotherapy and its type. 
Trabectedin was administered at $1.5 \mathrm{mg} / \mathrm{m}^{2}$ 24-hour continuous Intra-Venous (IV) infusion every three weeks.

\section{Clinical assessment}

Only patients who have been treated by at least 2 cycles of trabectedin were included for analysis efficacy. Patients were considered evaluable for efficacy if they had at least one assessment of tumor response.

The primary end-point was progression-free survival (PFS), defined as the time from the start of chemotherapy (trabectedin) to disease progression or death by any cause. PFS was analysed using the Kaplan-Meier method and was described using the median and 95\% confidence interval (Cl). The difference between two treatment arms was compared with the use of the log-rank test, with the hazard ratio and its $95 \%$ confidence interval calculated from a Cox regression model with a single covariate. Continuous variables were described by the mean standard deviation (SD) and median with range, and qualitative variables by the size and percentage rate. Between two cohorts, qualitative and quantitative variables were respectively compared by the Fisher exact test or the chi-square test and nonparametric Mann-Whitney test. All tests were two-tailed and significant at an alpha threshold of $5 \%$ ( $p$-value). Statistical analysis was performed with SAS ${ }^{\circledR}$ software version 9.4 (Cary, NC, USA)

Secondary end points were PFS at 3 months, PFS at 6 months, OS, response to the treatment and disease control. OS was defined as either the time from initiation of chemotherapy (trabectedin) to death from any cause or to last follow-up for survivors. Patients alive on April 01, 2020, the last date of analysis, were censored. Survival curves were estimated by the Kaplan-Meier method and were described using the median and $95 \% \mathrm{Cl}$. The response rate was primarily assessed by clinical examination or imaging, according to the Response Evaluation Criteria in Solid Tumors (RECIST 1.1) (11). Patients were classified as having a disease control if they had Complete Response (CR), Partial Response (PR), or Stable Disease (SD).

\section{Adverse events}

All patients who have been treated by at least 1 cycle of trabectedin were included for toxicities analysis. All toxicities were recorded, with their grading, according to the National Cancer Institute-Common Terminology Criteria for Adverse Events v4.0 (CTAE).

\section{Results}

Between January 2002 and August 2018, a total of 129 patients were treated by trabectedin (table 1). The median age was 59 years (ranged from 27 to 84 ) and 94 patients $(72.9 \%)$ had a good performance status (ECOG PS 0 or 1). Histological subtypes were leiomyosarcomas $(n=45,34.9 \%)$, liposarcomas $(n=30$, $23.2 \%)$, undifferentiated pleomorphic sarcomas $(n=19,14.7 \%)$, synovialosarcomas and solitary fibrous tumours (for each $n=7,5.4 \%$ ), and other subtypes $(n=21,16.3 \%)$ which included fibrosarcomas, angiosarcomas, chondrosarcomas, malignant phyllodes tumors, epithelioid haemangioendotheliomas 
and one osteosarcoma. Most of the patients had high grade (grade 2 plus 3 ) STS ( $n=76,58.9 \%)$. For 42 patients, the tumor grade was not available. Primary tumor sites included mainly the extremities $(n=53$, $41.1 \%)$ and retroperitoneum ( $n=24,18.6 \%)$. Patients had a median number of 2 lines of chemotherapy before trabectedin (ranged between: $0-8$ ) and one fifth of patients received it beyond the $2^{\text {nd }}$ line. The median number of cycles of trabectedin per patient was 3 (range: 1-79) with 29 patients receiving > 6 cycles (table 2).

Table 1: Characteristics of the patients. 


\begin{tabular}{|c|c|c|c|}
\hline \multicolumn{2}{|l|}{ Characteristics } & Number of patients & $\%$ \\
\hline Total & & 129 & 100 \\
\hline \multirow[t]{2}{*}{ Center } & Besançon & 54 & 42 \\
\hline & Dijon & 75 & 58 \\
\hline \multirow[t]{2}{*}{ Age (years) } & Median & & \\
\hline & Range & & \\
\hline \multirow[t]{2}{*}{ Gender } & Female & 73 & 56,6 \\
\hline & Male & 56 & 43.4 \\
\hline \multirow[t]{2}{*}{ Performance status } & $0-1$ & 94 & 72.9 \\
\hline & $2-3$ & 35 & 27.1 \\
\hline \multirow[t]{7}{*}{ Primary tumor site } & Extremity & 53 & 41.1 \\
\hline & Retroperitoneum & 24 & 18.6 \\
\hline & Trunk & 15 & 11.6 \\
\hline & Abdomen & 10 & 7.8 \\
\hline & Uterus & 9 & 6.9 \\
\hline & Axial skeleton & 4 & 3.1 \\
\hline & Others & 14 & 10.9 \\
\hline \multirow[t]{10}{*}{ Histology } & Leiomyosarcoma & 45 & 34.9 \\
\hline & Liposarcoma & 30 & 23.2 \\
\hline & Myxoid & 11 & 8.5 \\
\hline & UPS & 19 & 14.7 \\
\hline & Synovial sarcoma & 7 & 5.4 \\
\hline & Solitary fibrous tumour & 7 & 5.4 \\
\hline & Myxofibrosarcoma & 5 & 3.9 \\
\hline & Epithelioid sarcoma & 3 & 2.3 \\
\hline & Chondrosarcoma & 2 & 1.6 \\
\hline & Others histological subtypes & 11 & 8.5 \\
\hline Grade of the primary tumor & I & 11 & 8.5 \\
\hline
\end{tabular}




\begin{tabular}{|c|c|c|c|}
\hline & II & 39 & 30.2 \\
\hline & III & 37 & 28.7 \\
\hline & Missing data & 42 & 32.6 \\
\hline \multirow[t]{2}{*}{ Stage } & Locally advanced & 33 & 25.6 \\
\hline & Metastatic & 96 & 74.4 \\
\hline \multirow[t]{2}{*}{ Metastatic sites } & Lung & 60 & 46.5 \\
\hline & Others & 47 & 36.4 \\
\hline \multirow[t]{2}{*}{ Previous chemotherapy lines } & Median & & \\
\hline & Range & & \\
\hline
\end{tabular}

UPS = undifferentiated pleomorphic sarcoma

Table 2: Analysis of treatment with trabectedin (129 patients)

\begin{tabular}{|c|c|c|c|c|}
\hline & & & Number & $\%$ \\
\hline \multirow[t]{7}{*}{ Cycles of trabectedin } & Median & 3 & & \\
\hline & Range & $1-79$ & & \\
\hline & $<6$ cycles & & 85 & 65.9 \\
\hline & 6 cycles & & 15 & 11.6 \\
\hline & $>6$ cycles & & 29 & 22.5 \\
\hline & Median & 10 & & \\
\hline & Range & 7-79 & & \\
\hline \multirow[t]{2}{*}{ Trabectedin duration (months) } & Median & 2.1 & & \\
\hline & Range & $0.0-81.4$ & & \\
\hline \multirow[t]{3}{*}{ Causes of treatment discontinuation } & Progression & & 98 & 76.0 \\
\hline & Toxicity & & 15 & 11.6 \\
\hline & Others & & 16 & 12.4 \\
\hline
\end{tabular}

A total of 115 patients were evaluable for efficacy (table 3). At the cut-off date (April 01, 2020), 10 patients died prematurely, before their first assessment for response, 1 patient definitively stopped chemotherapy after only 1 cycle for renal failure and 3 patients have been lost. CR and PR were recorded as best response in $1(0.9 \%)$ and $10(8.7 \%)$ patients, respectively. A further 41 (35.6\%) patients had SD for a disease control rate of $45.2 \%$. 
Table 3: Efficacy (115 patients) 


\begin{tabular}{|c|c|c|c|}
\hline & & Number & $\%$ \\
\hline \multirow[t]{4}{*}{ Response rate } & $\mathrm{CR}$ & 1 & 0.9 \\
\hline & PR & 10 & 8.7 \\
\hline & SD & 41 & 35.6 \\
\hline & PD & 63 & 54.8 \\
\hline \multicolumn{2}{|l|}{ Disease control } & 52 & 45.2 \\
\hline Mean follow-up (months) & \multicolumn{3}{|c|}{6.4 [range: $0.7-80.1]$} \\
\hline \multicolumn{4}{|l|}{ Median PFS (months) } \\
\hline All patients $(n=115)$ & \multicolumn{3}{|c|}{$3.0\left[\mathrm{Cl}_{95 \%}: 2.3-4.7\right]$} \\
\hline Leiomyosarcoma $(\mathrm{n}=41)$ & \multicolumn{3}{|c|}{$2.8\left[\mathrm{Cl}_{95 \%}: 2.1-5.5\right]$} \\
\hline Liposarcoma outside myxoid $(n=17)$ & \multicolumn{3}{|c|}{$2.3\left[\mathrm{Cl}_{95 \%}: 1.7-4.3\right]$} \\
\hline UPS $(n=15)$ & \multicolumn{3}{|c|}{$3.7\left[\mathrm{Cl}_{95 \%}: 1.4-6.0\right]$} \\
\hline Myxoid liposarcoma (n=11) & \multirow{2}{*}{\multicolumn{3}{|c|}{$13.3\left[\mathrm{Cl}_{95 \%}: 2.3-18.7\right]$}} \\
\hline Synovialosarcoma $(n=6)$ & & & \\
\hline Solitary fibrous tumors $(n=6)$ & \multicolumn{3}{|c|}{$3.2\left[\mathrm{Cl}_{95 \%}: 1.6-29.5\right]$} \\
\hline Myxofibrosarcoma $(n=4)$ & \multicolumn{3}{|c|}{$7.4\left[\mathrm{Cl}_{95 \%}: 1.2-\ldots\right]$} \\
\hline Epithelioid sarcoma $(n=3)$ & \multicolumn{3}{|c|}{$1.7\left[\mathrm{Cl}_{95 \%}: 1.3-\ldots\right]$} \\
\hline Chondrosarcoma $(\mathrm{n}=2)$ & \multicolumn{3}{|c|}{$3.0\left[\mathrm{Cl}_{95 \%}: 2.4-3.2\right]$} \\
\hline \multirow[t]{2}{*}{ Others histological subtypes $(n=10)$} & \multicolumn{3}{|c|}{$1.6\left[\mathrm{Cl}_{95 \%}: 1.5-1.6\right]$} \\
\hline & \multicolumn{3}{|c|}{$2.3\left[\mathrm{Cl}_{95 \%}: 1.5-8.3\right]$} \\
\hline PFS at 3 months & \multicolumn{3}{|c|}{48.5} \\
\hline PFS at 6 months & \multicolumn{3}{|c|}{30.0} \\
\hline \multicolumn{4}{|l|}{ Median OS (months) } \\
\hline All patients $(n=115)$ & \multicolumn{3}{|c|}{$11.9\left[\mathrm{Cl}_{95 \%}: 10.2-16.6\right]$} \\
\hline Leiomyosarcoma $(\mathrm{n}=41)$ & \multicolumn{3}{|c|}{$17.3\left[\mathrm{Cl}_{95 \%}: 8.4-22.9\right]$} \\
\hline Liposarcoma outside myxoid $(n=17)$ & \multicolumn{3}{|c|}{$9.1\left[\mathrm{Cl}_{95 \%}: 3.5-13.2\right]$} \\
\hline UPS ( $n=15)$ & \multicolumn{3}{|c|}{$13.2\left[\mathrm{Cl}_{95 \%}: 7.0-23.0\right]$} \\
\hline Myxoid liposarcoma $(n=11)$ & \multirow{2}{*}{\multicolumn{3}{|c|}{$27.8\left[\mathrm{Cl}_{95 \%}: 3.2-64.7\right]$}} \\
\hline Synovialosarcoma $(n=6)$ & & & \\
\hline
\end{tabular}




\begin{tabular}{|llll|} 
Solitary fibrous tumors $(\mathrm{n}=6)$ & $5.8\left[\mathrm{Cl}_{95 \%}: 3.7-54.4\right]$ & \\
Myxofibrosarcoma $(\mathrm{n}=4)$ & $17.1\left[\mathrm{Cl}_{95 \%}: 3.8-\ldots\right]$ & \\
Epithelioid sarcoma $(\mathrm{n}=3)$ & $16.2\left[\mathrm{Cl}_{95 \%}: 1.8-\ldots\right]$ & \\
Chondrosarcoma $(\mathrm{n}=2)$ & $3.5\left[\mathrm{Cl}_{95 \%}: 3.2-4.0\right]$ & \\
Others histological subtypes $(\mathrm{n}=10)$ & $7.2\left[\mathrm{Cl}_{95 \%}: 2.6-11.9\right]$ & \\
& $11.4\left[\mathrm{Cl}_{95 \%}: 2.4-12.7\right]$ & \\
& & 93 & 80.9 \\
\hline Death & Tumor progression & 83 & 72.2 \\
\hline Causes of death & Adverse events & 4 & 3.5 \\
\cline { 2 - 4 } & Not specified & 6 & 5.2 \\
\hline
\end{tabular}

$\mathrm{CR}=$ complete response, $\mathrm{PR}=$ partial response, $\mathrm{SD}=$ stable disease, $\mathrm{PD}=$ progression disease, $\mathrm{PFS}=$ progression-free survival, OS = overall survival, UPS = undifferentiated pleomorphic sarcoma

With of mean follow-up of 6.4 months [0.7 - 80.1], median PFS was 3.0 months [Cl ${ }_{95 \%}: 2.3-4.7$ ] (figure1). However, the 3-months PFS rate and the 6-months PFS rate were respectively $48.5 \%$ and $30 \%$. Median OS was 11.9 months [ $\mathrm{Cl}_{95 \%}: 10.2-16.6$ ], and at the end of the follow-up period, about one fifth of the evaluation patients were still alive (figure 2).

There was no significant difference in PFS comparing with sex, performance status (0-1 vs 2-3), grade (1 vs 2-3), age, center or liposarcoma and leiomyosarcoma [L-sarcoma] vs other types (figure 3). On the other hand, there is a very favourable impact of certain histological subtypes, in particular myxoid liposarcomas ( $\mathrm{n}=11)$ with not only an increase in median PFS compared with other histological subtypes (13.3 months [Cl95\%: 2.3 - 18.7] vs 2.8 months [Cl95\%: 2.3 - 4.4]) but also an improvement in median OS (27.8 months [CI95\%: 3.2 - 64.7] vs 11.1 months [CI95\%: 9.3 - 13.8]) (figure 4).

Forty-four patients received at least 6 trabectedin cycles. Of these, 15 stopped the chemotherapy (interruption group) and 29 continued the same protocol (maintenance group). In maintenance group, the median number of cycles was 10, with a maximum of 79 in a woman treated for an undifferentiated pleomorphic sarcoma. The evolution of the 2 groups differs frankly. All patients, in the interruption group, had their disease progressing or died by any cause. Whereas, 4 patients were alive without PD in the maintenance group. In addition, median PFS increased significantly in favor of therapeutic maintenance: 10.2 months $\left[\mathrm{Cl}_{95 \%}: 7.7-13.6\right]$ versus 5.5 months $\left(\left[\mathrm{Cl}_{95 \%}: 4.4-6.4\right], \mathrm{p}=0.006\right)$. But, no difference on the median OS was recorded (figure 5).

Toxicities could be reported for 129 patients (table 4). Elevation of transaminases were usual and transient. Severe clinical toxicities like fatigue or nausea were also found, in $1.3 \%$ and $2.3 \%$ of cases, 
respectively. Seven percent of febrile neutropenia was noticed but one patient died due to trabectedinrelated febrile neutropenia. In total, 4 fatal outcomes related to treatment had been reported. Unusually, three patients died due to trabectedin-related renal failure in a context of general physical health deterioration. In addition, one patient died due to trabectedin-related colitis.

Table 4: Safety: grade 3-4 adverse events (129 patients)

\begin{tabular}{|cll|}
\hline & Number & $\%$ \\
\hline Clinical & & \\
\hline Nausea & 3 & 2.3 \\
\hline Vomiting & 0 & 0.0 \\
\hline Fatigue & 1 & 1.3 \\
\hline Mucitis & 0 & 0.0 \\
\hline Diarrhea & 0 & 0.0 \\
\hline Constipation & 0 & 0.0 \\
\hline Hematologic & & \\
\hline Neutropenia & 41 & 31.8 \\
\hline Febrile neutropenia & 9 & 7.0 \\
\hline Thrombocytopenia & 16 & 12.4 \\
\hline Anemia & 6 & 4.7 \\
\hline Liver abnormalities & & \\
\hline Cytolysis & 22 & 17.1 \\
\hline GGT & 35 & 27.1 \\
\hline Rhabdomyolysis & 3 & 2.3 \\
\hline
\end{tabular}

\section{Discussion}

With the exception of gastrointestinal stromal tumors (GIST), the prognostic of patients treated for locally advanced and metastatic STS remains poor. In all clinical guidelines, management of sarcoma patients should be discussed and carried out within a dedicated multidisciplinary team. Despite a management in expert centres, the median of overall survival is 18 months (12). The various palliative treatments may include surgery (for example, pulmonary metastasis), radiotherapy and especially chemotherapy (13). Nowadays, second lines after failure of doxorubicin and/or ifosfamide include others regimens like dacarbazine alone or in combination, eribulin for liposarcomas, gemcitabine alone or in combination with 
docetaxel for leiomyosarcomas and undifferentiated pleomorphic sarcomas, paclitaxel for angiosarcomas or pazopanib (14-18). In the end, few drugs have been approved for STS treatment, and the arrival of trabectedin in 2007 in second and/or beyond line treatment set a new course (19).

Our results, showing a median PFS of 3 months $\left[\mathrm{Cl}_{95 \%}: 2.3-4.7\right]$ and a median OS of 11.9 months $\left[\mathrm{Cl}_{95 \%}\right.$ : 10.2-16.6], are fully compliant with the literature data. Demetri et al. published the results of a STS - 201 phase II study in 2009 that showed the superiority of trabectedin regimens every 3 weeks versus every week. They obtained a median PFS of 3.3 months and median OS of 13.9 months in 3 weeks 24-hour arm (10). Other phase II studies found similar results (20-22). Most recently, a prospective randomized phase III trial T-SAR comparing trabectedin versus best supportive care (BSC) in patients with pre-treated advanced STS, was presented to ESMO 2016 (23). Median PFS and median OS were 3.1 months $\left[\mathrm{Cl}_{95 \%}\right.$ : 1.8-5.9] and 13.6 months [ $\left.\mathrm{Cl}_{95 \%}: 7.1-17.3\right]$ respectively in trabectedin arm. Finally, several RWE studies have already been published including a slightly larger population than in the pivotal studies: no limit neither for the number of lines of previous chemotherapy, nor for the histological subtypes (24-28). They found a median PFS between 3.6 and 5.9 months and a median OS between 11.9 and 21.3 months.

Based on the European Organization for Research and Treatment of Cancer (EORTC) experiment, Van Oosterom et al. and Van Glabbeke et al. proposed PFS rates at 3 and 6 months as end points for detected effective/ineffective treatments in phase II trials $(19,20)$. A drug is considered active if it allows $3-$ and $6-$ month PFS rates $>39 \%$ and $14 \%$, respectively, as second-line regimens. In our retrospective study, the 3months PFS rate and the 6 -months PFS rate were respectively $48.5 \%$ and $30.0 \%$, comparable to the other publications.

To date, one major concern in STS treatment is that no predictive nor prognostic biomarker can be routinely used. In this retrospective analyse, no clinical or tumoral parameter was significantly associated with PFS and OS. Trabectedin administration resulted in a median PFS of 3.1 months $\left[\mathrm{Cl}_{95 \%}: 2.0-5.3\right]$ in L-sarcoma arm versus 2.8 months [ $\mathrm{Cl}_{95 \%}: 2.3-5.0$ ] in other subtypes arm, a median OS of 11.4 months [Cl $\mathrm{Cl}_{95 \%}$ : 7.0-13.2] versus 13.8 months [ $\mathrm{Cl}_{95 \%}:$ 9.3-18.8]. However, it is now assumed that the histological subtypes liposarcoma and leiomyosarcoma are particularly sensitive to trabectedin. This concept comes in particular from the results of pivotal phase II and III studies including exclusively patients treated for Lsarcomas $(10,29)$. In the prospective multicenter phase III trial SAR - 3007, 518 patients were randomized between trabectedin to dacarbazine, after failure conventional chemotherapy. The median PFS was 4.2 months with a reduction in progression risk of $45 \%$ in favor of trabectedin. On the other hand, there is no difference on the median of OS. This sensitivity of L-sarcomas is well demonstrated in the T-SAR study (23). Inclusions were not limited to patients treated for liposarcomas or leiomyosarcomas. The median PFS of the trabectedin arm for all histological subtypes was 3.1 months [ $\left[\mathrm{C}_{95 \%}: 1.8-5.9\right]$, while it was 5.1 months [I $\left.\mathrm{I}_{95 \%}: 2-8.3\right]$ for $\mathrm{L}$-sarcomas subtype ( $\mathrm{n}=32$ patients) and 1.8 months [IC $\left.{ }_{95 \%}: 0.7-3.1\right]$ for others subtypes ( $n=20$ patients). There was no difference in OS between the different groups, trabectedin arm and BSC arm. Finally, all these results are really superposable, highlighting the ubiquitous action of trabectedin with more sensitive subtypes than others like L-sarcomas - especially myxoid liposarcomas 
(MLP) - and also solitary fibrous tumors (30-32). In our study, 11 patients were treated with trabectedin for MLP. The median PFS was remarkable with 13.3 months [ $\left.\mathrm{Cl}_{95 \%}: 2.3-18.7\right]$ versus 2.8 months $\left[\mathrm{Cl}_{95 \%}\right.$ : 2.3-4.4] for all other patients with a significant improvement $(p=0.02)$. Equally interesting, this difference was also found for the median OS: 27.8 months [ $\left.\mathrm{Cl}_{95 \%}: 3.2-64.7\right]$ versus 11.1 months ([ $\mathrm{Cl}_{95} \%$ : $9.3-13.8], p=0.02$ ). Already in 2007, 51 patients with advanced pretreated MLP at five international institutions in a compassionate-use programme were analysed retrospectively (30). After a follow-up of 14.0 months, the objective response rate was $51 \%$ and the median of PFS was 14.0 months [IC ${ }_{95 \%}: 13.1-$ 21.0]. This specific subtype is characterized by the existence of the fusion gene DDIT3-FUS and the very high effectiveness of trabectedin against MLP seems to be correlated to its ability to counteract the activity of chimeric oncoprotein. By extrapolation, other histological subtypes with translocation-related sarcomas (synovial sarcoma, alveolar soft part sarcoma, endometrial stromal sarcoma and clear cell sarcoma) were evaluated in a retrospective analysis giving promising results (33).

Another highlight is the interest of ongoing treatment. Even if few patients were concerned, observations can be drawn. After the first 6 cycles, 2 opposing strategies can be chosen; either to stop or to continue trabectedin until intolerance or tumour progression. About a quarter of the patients received more than 6 cycles of trabectedin, which an acceptable toxicity allowing prolonged treatment. The evolution of the 2 groups differs: median PFS was doubled in favor of therapeutic maintenance. On the other hand, no difference on the median OS was observed. This finding is already documented by the T-DIS study, a randomised phase 2 trial (34). Median PFS was 7.2 months $\left[\mathrm{Cl}_{95 \%}: 4.0-12.7\right]$ in the continuation group versus 4.0 months $\left[\mathrm{Cl}_{95 \%}: 2.5-5.5\right]$ in the interruption group, with a significant improvement (HR: 1.97 [Cl$\left.\left.{ }_{95 \%}: 1.09-3.54\right], \mathrm{p}=0.02\right)$. Nonetheless, in our retrospective study, probable bias exists: no randomization, patients who continued chemotherapy were certainly patients where the benefit/tolerance balance was the most favourable, and few number of patients (29 patients in the maintenance group and 15 in the interruption group).

In terms of toxicities, most of them were expected and manageable, non - cumulative, mainly summarized by haematological and hepatological failures, and consistent with the previous T - SARC randomized trial (23). Thirty four percent of patients used granulocyte colony-stimulating factors which were $28 \%$ in the Demetri et al. study (10). Other toxicities were quite similarly to the results of the current publications (35-37).

This study had some limitations. The retrospective design made comparisons with previous randomized control trial difficult because the study population and follow-up may differ. For example, the enrolment and treatment criteria of our study were less restrictive with more pretreated patients and other histological subtypes than liposarcomas and leiomyosarcomas. In addition, dose reductions, treatment delays and tumor evaluations depended on the physician's choice. The small number of patients and missing data limited the analysis, in particular the association between different histological subtypes and clinical outcomes. Finally, there was no provision for a quality-of-life assessment Despite these limitations, this study is representative of the general population because it included patients treated in 2 
centers with different medical situations, and these results could be considered to represent assessment of trabectedin effectiveness in the real-world clinical conditions.

\section{Conclusion}

In conclusion, strategies of treatment after conventional drugs remain subject to debate for advanced or metastatic STS. Independently from the necessary need to take the histological and molecular subtypes into account, the choice of the best regimen has to integrate the tumor molecular characterisation, and probably cost effectiveness and quality of life. Nevertheless, trabectedin seems to remain interesting in terms of clinical benefit and low toxicity. It has to be confirmed in larger randomised trials containing recent strategies.

\section{Declarations}

\section{Ethics approval and consent to participate}

This retrospective study was approved by Institutional Review Board of the Regional Cancer Institute (University Hospital of Besancon, France). Written informed consent was obtained from all alive study subjects. The study was performed in accordance with the Declaration of Helsinki.

\section{Consent for publication}

Not applicable

\section{Availability of data and materials}

The datasets used and/or analysed during the current study are available from the corresponding author on reasonable request.

\section{Competing interests}

The authors declare that they have no competing interests.

\section{Funding}

None.

\section{Authors' contributions}


$\mathrm{CL}, \mathrm{JM}, \mathrm{NV}, \mathrm{HA}, \mathrm{AS}, \mathrm{CBC}, \mathrm{MG}, \mathrm{NF}, \mathrm{KE}$, IN were involved in making substantial contributions to the conception or design of the work, analysis, or interpretation of data.

$\mathrm{CL}, \mathrm{JM}, \mathrm{NV}$ wrote the main manuscript text.

$\mathrm{CL}, \mathrm{JM}, \mathrm{NV}, \mathrm{HA}, \mathrm{AS}, \mathrm{CBC}, \mathrm{MG}, \mathrm{NF}, \mathrm{KE}, \mathrm{IN}$ reviewed the manuscript.

\section{Acknowledgements}

None.

\section{References}

1. Fletcher CDM. The evolving classification of soft tissue tumours - an update based on the new 2013 WHO classification. Histopathology. 2014 Jan;64(1):2-11.

2. Anderson WJ, Doyle LA. Updates from the 2020 World Health Organization Classification of Soft Tissue and Bone Tumours. Histopathology. 2021 Jan 12;

3. Coindre JM, Terrier P, Guillou L, Le Doussal V, Collin F, Ranchère D, et al. Predictive value of grade for metastasis development in the main histologic types of adult soft tissue sarcomas: a study of 1240 patients from the French Federation of Cancer Centers Sarcoma Group. Cancer. 2001 May 15;91(10):1914-26.

4. Mouridsen HT, Bastholt L, Somers R, Santoro A, Bramwell V, Mulder JH, et al. Adriamycin versus epirubicin in advanced soft tissue sarcomas. A randomized phase II/phase III study of the EORTC Soft Tissue and Bone Sarcoma Group. Eur J Cancer Clin Oncol. 1987 Oct;23(10):1477-83.

5. Karavasilis V, Seddon BM, Ashley S, Al-Muderis O, Fisher C, Judson I. Significant clinical benefit of first-line palliative chemotherapy in advanced soft-tissue sarcoma: retrospective analysis and identification of prognostic factors in 488 patients. Cancer. 2008 Apr 1;112(7):1585-91.

6. Borden EC, Amato DA, Rosenbaum C, Enterline HT, Shiraki MJ, Creech RH, et al. Randomized comparison of three adriamycin regimens for metastatic soft tissue sarcomas. J Clin Oncol. 1987 Jun;5(6):840-50.

7. Tursz T. High-dose ifosfamide in the treatment of advanced soft tissue sarcomas. Semin Oncol. 1996 Jun;23(3 Suppl 7):34-9.

8. Pommier Y, Kohlhagen G, Bailly C, Waring M, Mazumder A, Kohn KW. DNA sequence- and structureselective alkylation of guanine N2 in the DNA minor groove by ecteinascidin 743, a potent antitumor compound from the Caribbean tunicate Ecteinascidia turbinata. Biochemistry. 1996 Oct 15;35(41):13303-9.

9. Furuta T, Ueda T, Aune G, Sarasin A, Kraemer KH, Pommier Y. Transcription-coupled nucleotide excision repair as a determinant of cisplatin sensitivity of human cells. Cancer Res. $2002 \mathrm{Sep}$ 1;62(17):4899-902. 
10. Demetri GD, Chawla SP, von Mehren M, Ritch P, Baker LH, Blay JY, et al. Efficacy and safety of trabectedin in patients with advanced or metastatic liposarcoma or leiomyosarcoma after failure of prior anthracyclines and ifosfamide: results of a randomized phase II study of two different schedules. J Clin Oncol. 2009 Sep 1;27(25):4188-96.

11. Therasse P, Arbuck SG, Eisenhauer EA, Wanders J, Kaplan RS, Rubinstein L, et al. New guidelines to evaluate the response to treatment in solid tumors. European Organization for Research and Treatment of Cancer, National Cancer Institute of the United States, National Cancer Institute of Canada. J Natl Cancer Inst. 2000 Feb 2;92(3):205-16.

12. Italiano A, Mathoulin-Pelissier S, Cesne AL, Terrier P, Bonvalot S, Collin F, et al. Trends in survival for patients with metastatic soft-tissue sarcoma. Cancer. 2011 Mar 1;117(5):1049-54.

13. Falk AT, Moureau-Zabotto L, Ouali M, Penel N, Italiano A, Bay J-O, et al. Effect on survival of local ablative treatment of metastases from sarcomas: a study of the French sarcoma group. Clin Oncol (R Coll Radiol). 2015 Jan;27(1):48-55.

14. García-Del-Muro X, López-Pousa A, Maurel J, Martín J, Martínez-Trufero J, Casado A, et al. Randomized phase Il study comparing gemcitabine plus dacarbazine versus dacarbazine alone in patients with previously treated soft tissue sarcoma: a Spanish Group for Research on Sarcomas study. J Clin Oncol. 2011 Jun 20;29(18):2528-33.

15. Schöffski P, Chawla S, Maki RG, Italiano A, Gelderblom H, Choy E, et al. Eribulin versus dacarbazine in previously treated patients with advanced liposarcoma or leiomyosarcoma: a randomised, openlabel, multicentre, phase 3 trial. Lancet. 2016 Apr 16;387(10028):1629-37.

16. Maki RG, Wathen JK, Patel SR, Priebat DA, Okuno SH, Samuels B, et al. Randomized phase II study of gemcitabine and docetaxel compared with gemcitabine alone in patients with metastatic soft tissue sarcomas: results of sarcoma alliance for research through collaboration study 002 [corrected]. $J$ Clin Oncol. 2007 Jul 1;25(19):2755-63.

17. Penel N, Italiano A, Ray-Coquard I, Chaigneau L, Delcambre C, Robin YM, et al. Metastatic angiosarcomas: doxorubicin-based regimens, weekly paclitaxel and metastasectomy significantly improve the outcome. Ann Oncol. 2012 Feb;23(2):517-23.

18. van der Graaf WTA, Blay J-Y, Chawla SP, Kim D-W, Bui-Nguyen B, Casali PG, et al. Pazopanib for metastatic soft-tissue sarcoma (PALETTE): a randomised, double-blind, placebo-controlled phase 3 trial. Lancet. 2012 May 19;379(9829):1879-86.

19. Casali PG, Abecassis N, Aro HT, Bauer S, Biagini R, Bielack S, et al. Soft tissue and visceral sarcomas: ESMO-EURACAN Clinical Practice Guidelines for diagnosis, treatment and follow-up. Ann Oncol. 2018 Oct 1;29(Suppl 4):iv268-9.

20. Garcia-Carbonero R, Supko JG, Manola J, Seiden MV, Harmon D, Ryan DP, et al. Phase II and pharmacokinetic study of ecteinascidin 743 in patients with progressive sarcomas of soft tissues refractory to chemotherapy. J Clin Oncol. 2004 Apr 15;22(8):1480-90.

21. Yovine A, Riofrio M, Blay JY, Brain E, Alexandre J, Kahatt C, et al. Phase II study of ecteinascidin-743 in advanced pretreated soft tissue sarcoma patients. J Clin Oncol. 2004 Mar 1;22(5):890-9. 
22. Le Cesne A, Blay JY, Judson I, Van Oosterom A, Verweij J, Radford J, et al. Phase Il study of ET-743 in advanced soft tissue sarcomas: a European Organisation for the Research and Treatment of Cancer (EORTC) soft tissue and bone sarcoma group trial. J Clin Oncol. 2005 Jan 20;23(3):576-84.

23. Le Cesne A, Blay JY, Cupissol D, Italiano A, Delcambre C, Penel N, et al. Results of a prospective randomized phase III T-SAR trial comparing trabectedin (T) vs best supportive care (BSC) in patients with pretreated advanced soft tissue sarcoma (ASTS): A French Sarcoma Group (FSG) trial. Available from: JCO.2018.36.15_suppl.11508

24. Blay J-Y, Italiano A, Ray-Coquard I, Le Cesne A, Duffaud F, Rios M, et al. Long-term outcome and effect of maintenance therapy in patients with advanced sarcoma treated with trabectedin: an analysis of 181 patients of the French ATU compassionate use program. BMC Cancer. 2013 Feb 6;13:64.

25. Samuels BL, Chawla S, Patel S, von Mehren M, Hamm J, Kaiser PE, et al. Clinical outcomes and safety with trabectedin therapy in patients with advanced soft tissue sarcomas following failure of prior chemotherapy: results of a worldwide expanded access program study. Ann Oncol. 2013 Jun;24(6):1703-9.

26. Le Cesne A, Ray-Coquard I, Duffaud F, Chevreau C, Penel N, Bui Nguyen B, et al. Trabectedin in patients with advanced soft tissue sarcoma: a retrospective national analysis of the French Sarcoma Group. Eur J Cancer. 2015 Apr;51(6):742-50.

27. Buonadonna A, Benson C, Casanova J, Kasper B, López Pousa A, Mazzeo F, et al. A noninterventional, multicenter, prospective phase IV study of trabectedin in patients with advanced soft tissue sarcoma. Anticancer Drugs. 2017 Nov;28(10):1157-65.

28. Kobayashi H, Iwata S, Wakamatsu T, Hayakawa K, Yonemoto T, Wasa J, et al. Efficacy and safety of trabectedin for patients with unresectable and relapsed soft-tissue sarcoma in Japan: A Japanese Musculoskeletal Oncology Group study. Cancer. 2020 Mar 15;126(6):1253-63.

29. Patel S, von Mehren M, Reed DR, Kaiser P, Charlson J, Ryan CW, et al. Overall survival and histologyspecific subgroup analyses from a phase 3 , randomized controlled study of trabectedin or dacarbazine in patients with advanced liposarcoma or leiomyosarcoma. Cancer. 2019 Aug 1;125(15):2610-20.

30. Grosso F, Jones RL, Demetri GD, Judson IR, Blay J-Y, Le Cesne A, et al. Efficacy of trabectedin (ecteinascidin-743) in advanced pretreated myxoid liposarcomas: a retrospective study. Lancet Oncol. 2007 Jul;8(7):595-602.

31. Khalifa J, Ouali M, Chaltiel L, Le Guellec S, Le Cesne A, Blay J-Y, et al. Efficacy of trabectedin in malignant solitary fibrous tumors: a retrospective analysis from the French Sarcoma Group. BMC Cancer. 2015 Oct 15;15:700.

32. Penel N, Decoupigny E, Tresch-Bruneel E, Le Cesne A, Taieb S, Isambert N. Exceptional Long-lasting Clinical Benefit of Trabectedin in a Patient With Metastatic Undifferentiated Pleomorphic Sarcoma: Postscriptum From the T-Dis Trial. Am J Clin Oncol. 2019 Sep;42(9):737. 
33. Le Cesne A, Cresta S, Maki RG, Blay JY, Verweij J, Poveda A, et al. A retrospective analysis of antitumour activity with trabectedin in translocation-related sarcomas. Eur J Cancer. 2012 Nov;48(16):3036-44.

34. Le Cesne A, Blay J-Y, Domont J, Tresch-Bruneel E, Chevreau C, Bertucci F, et al. Interruption versus continuation of trabectedin in patients with soft-tissue sarcoma (T-DIS): a randomised phase 2 trial. Lancet Oncol. 2015 Mar;16(3):312-9.

35. Pautier P, Floquet A, Chevreau C, Penel N, Guillemet C, Delcambre C, et al. Trabectedin in combination with doxorubicin for first-line treatment of advanced uterine or soft-tissue leiomyosarcoma (LMS-02): a non-randomised, multicentre, phase 2 trial. Lancet Oncol. 2015 Apr;16(4):457-64.

36. Jones RL, Demetri GD, Schuetze SM, Milhem M, Elias A, Van Tine BA, et al. Efficacy and tolerability of trabectedin in elderly patients with sarcoma: subgroup analysis from a phase III, randomized controlled study of trabectedin or dacarbazine in patients with advanced liposarcoma or leiomyosarcoma. Ann Oncol. 2018 Sep 1;29(9):1995-2002.

37. Grosso F, D’Ambrosio L, Zucchetti M, Ibrahim T, Tamberi S, Matteo C, et al. Pharmacokinetics, safety, and activity of trabectedin as first-line treatment in elderly patients who are affected by advanced sarcoma and are unfit to receive standard chemotherapy: A phase 2 study (TR1US study) from the Italian Sarcoma Group. Cancer. 2020 Nov 1;126(21):4726-34.

\section{Figures}




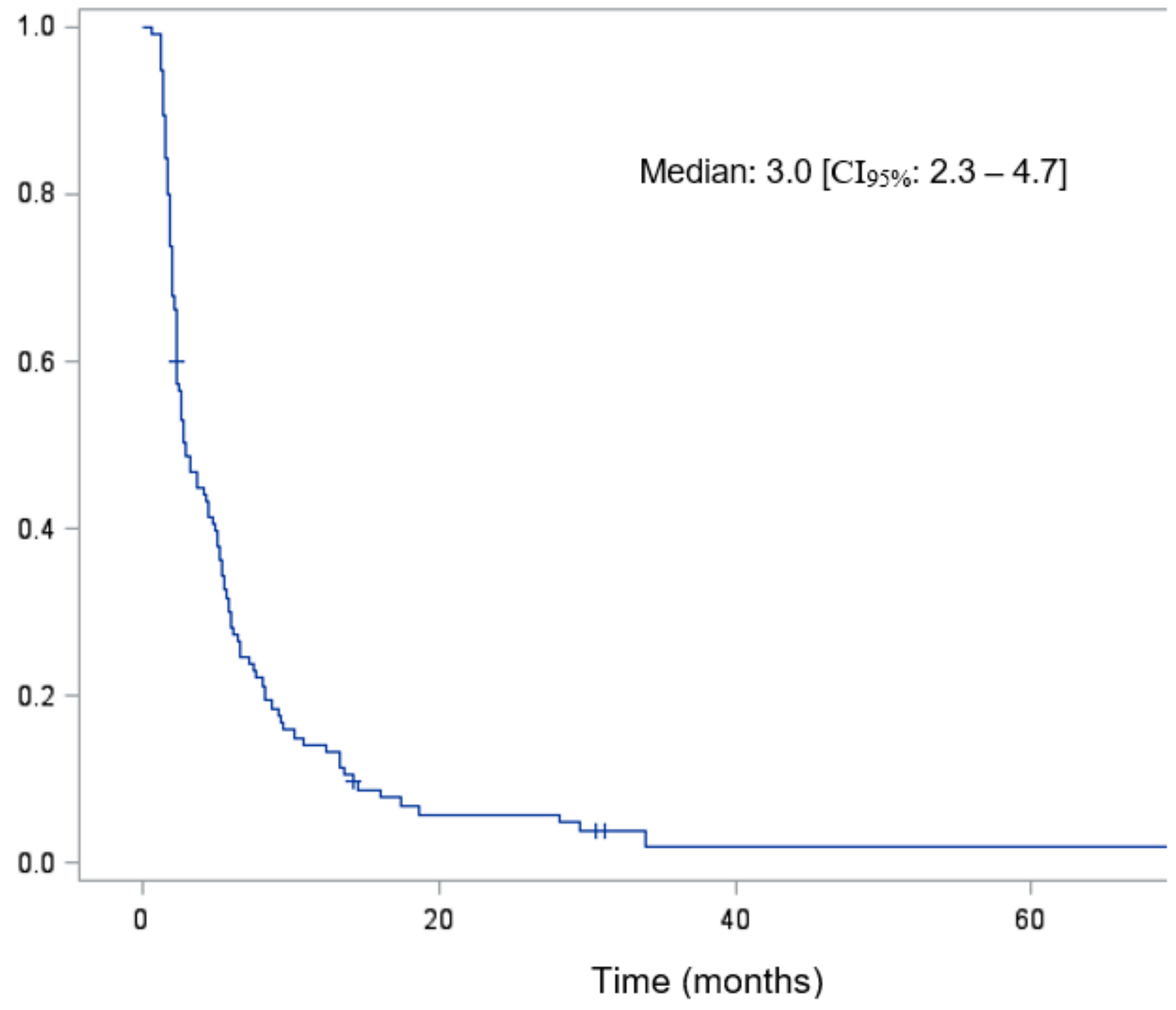

Figure 1

Progression-free survival (115 patients) 


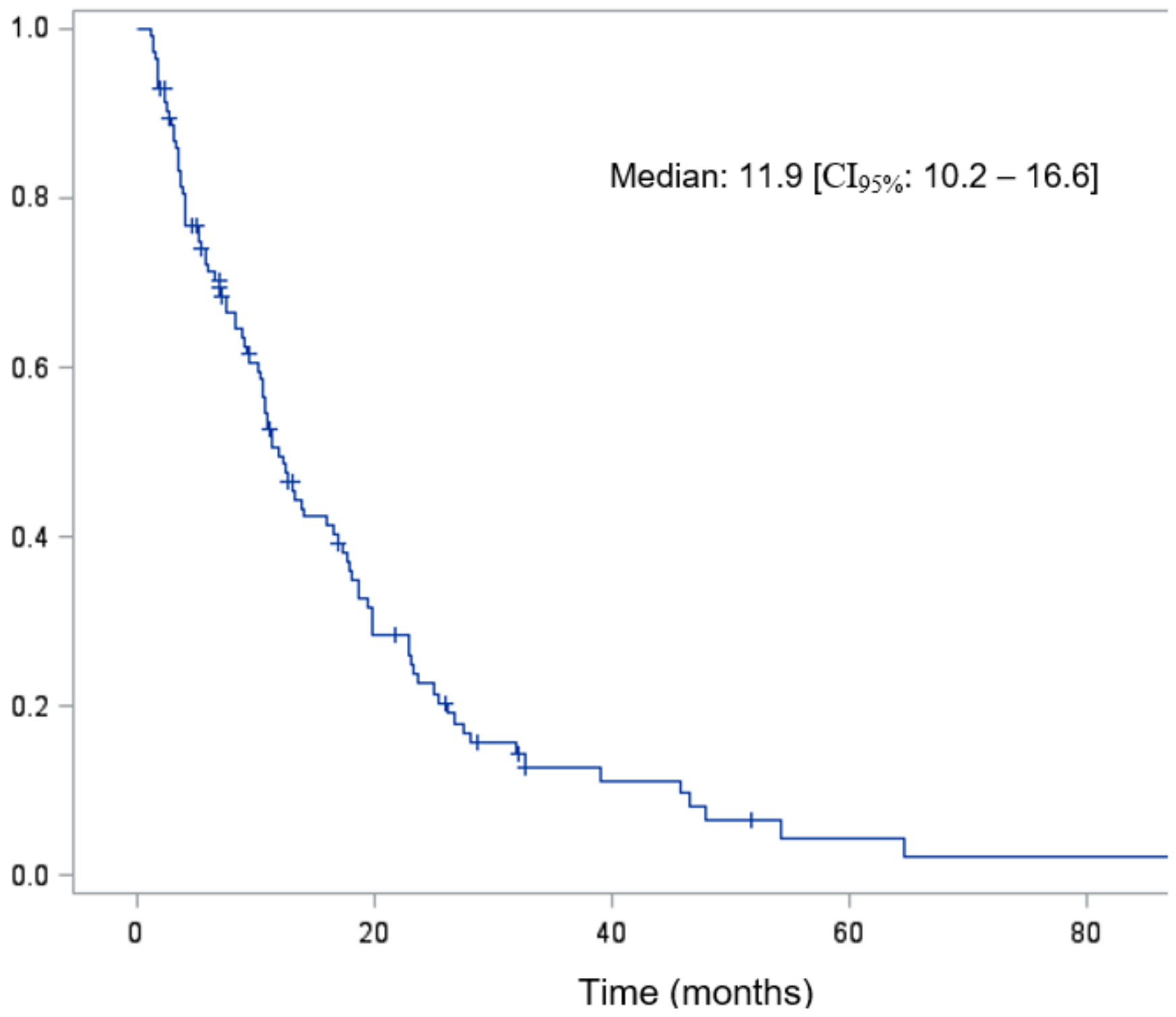

Figure 2

Overall survival (115 patients) 

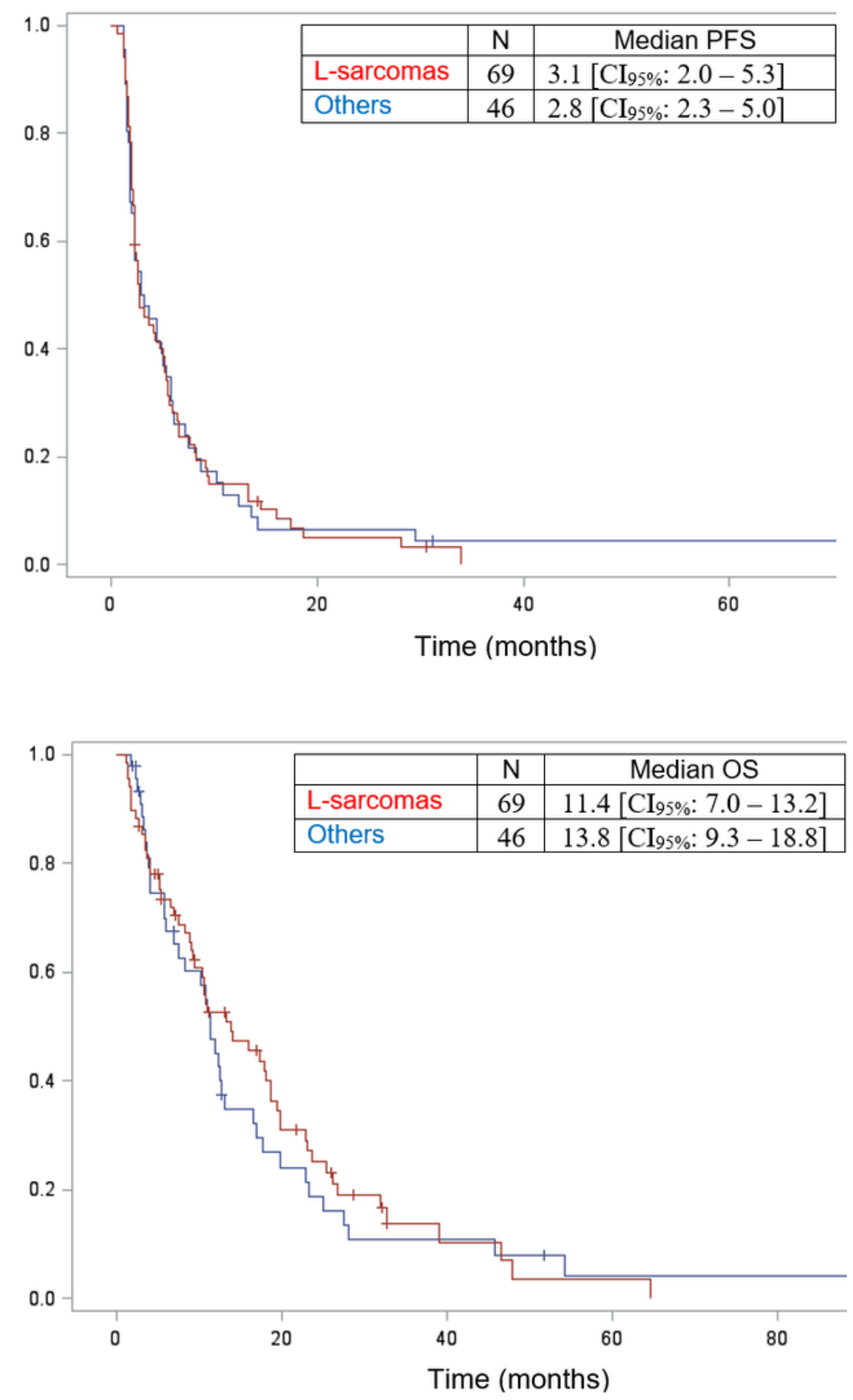

Figure 3

Progression-free survival (PFS) and overall survival (OS) of L-sarcoma versus other sarcomas 

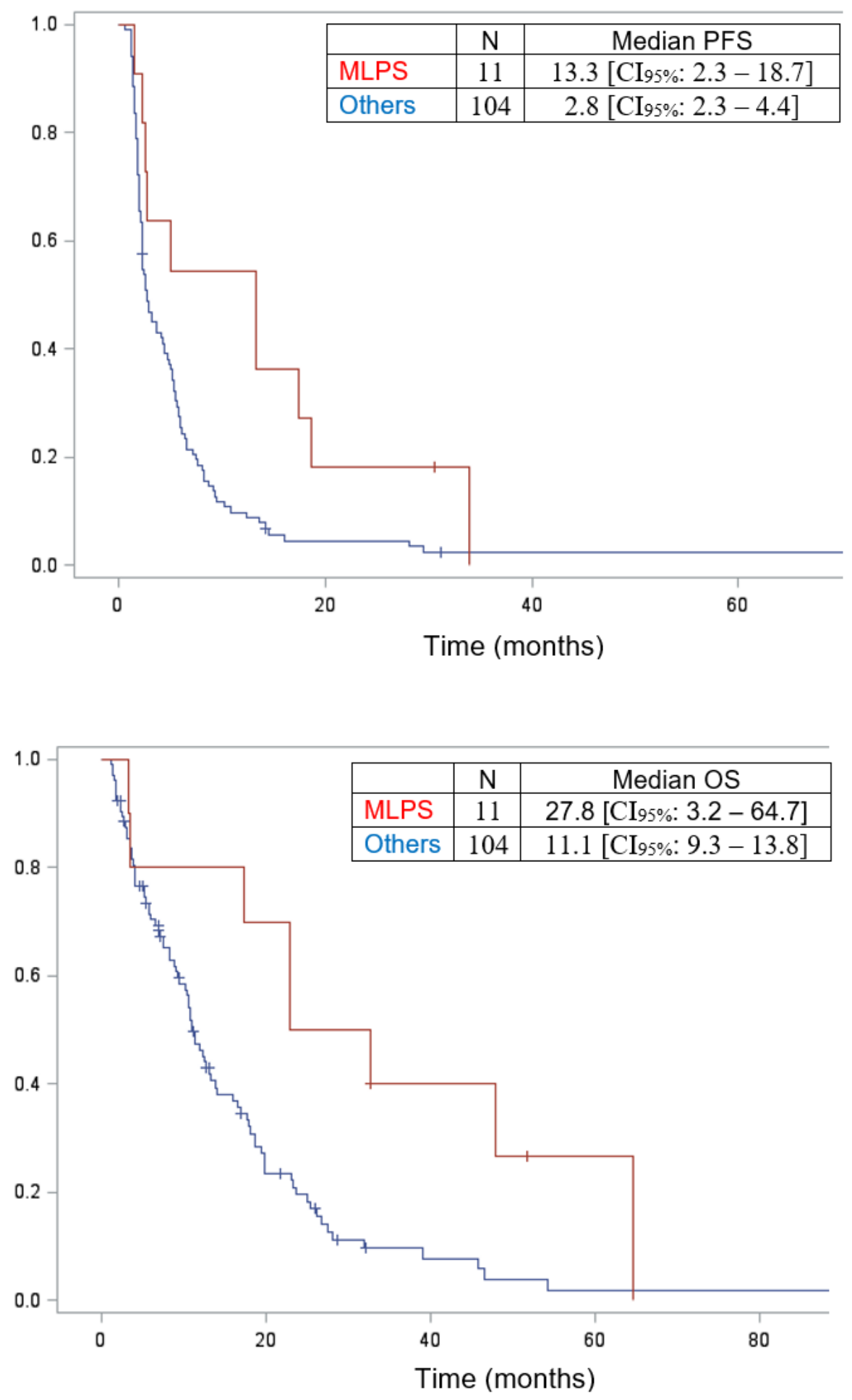

Figure 4

Progression-free survival (PFS) and overall survival (OS) of myxoid liposarcomas (MLPS) versus others 

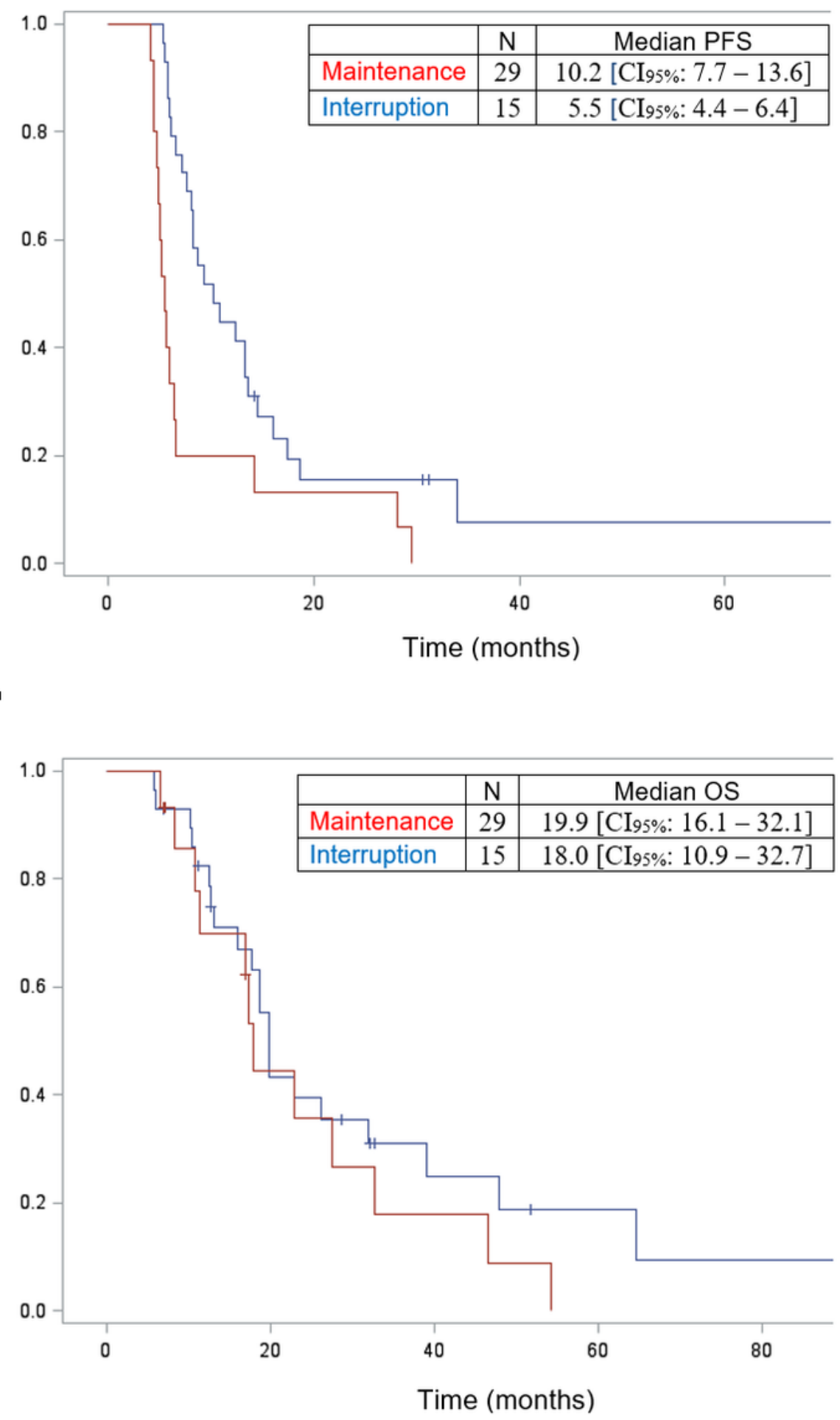

Figure 5

Progression-free survival (PFS) and overall survival (OS) of maintenance group versus interruption group 